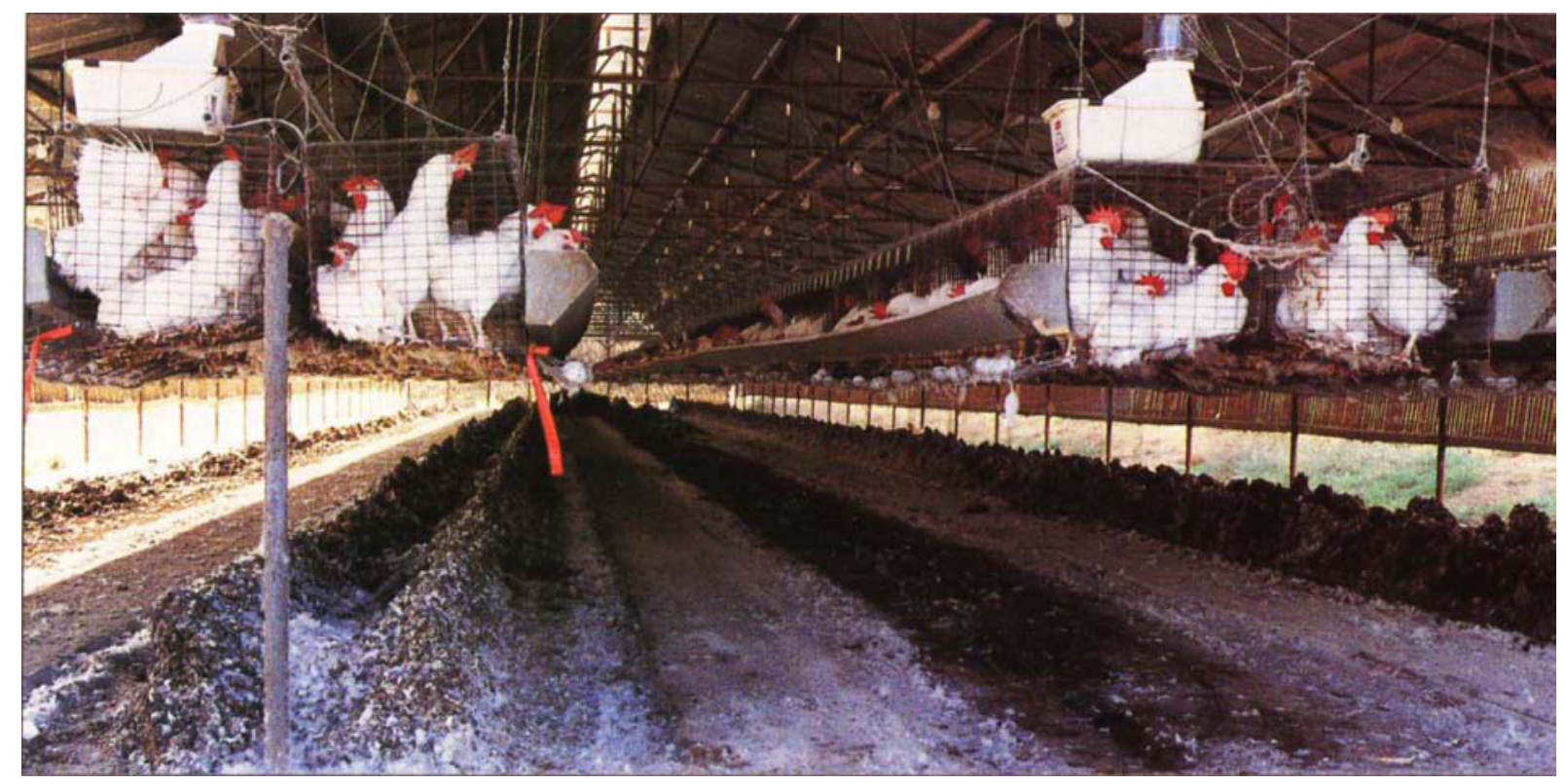

Egg producers sometimes remove poultry manure in a pattern of alternating rows. However, the study indicates that such removal systems do not necessarily reduce fly populations.

\title{
Managing manure and conserving predators helps control flies in caged-layer poultry systems
}

\author{
Bradley A. Mullens
}

\begin{abstract}
As the rural-urban interface expands, controlling flies has become increasingly important on California poultry farms. Manure management is a critical component of keeping fly populations in check. Recent research demonstrates that the dry pad left behind after manure cleanouts in cagedlayer poultry systems aids manure drying because of the elevation and improved airflow. Most mites and beetles that prey on fly eggs and larvae are removed in a cleanout, although predator populations require longer than flies to recover. Leaving undisturbed manure (with a larger number of predators) adjacent to recently removed manure did not improve fly control significantly in open-sided layer houses, but might be more important in fully enclosed houses.
\end{abstract}

Doultry manure supports the devel1 opment of several serious fly pests (Axtell and Arends 1990). Fresh manure is rich in nutrients and is produced at the rate of one-quarter pound per hen per day, providing an ideal habitat for fly larvae to live and feed. The problem has become more acute in modern high-density poultry housing where manure often is concentrated in piles below the birds. The house fly (Musca domestica), most abundant in summer and fall, is the most important worldwide fly pest. Two smaller flies (Fannia canicularis and $F$. femoralis) are also common in poultry manure in California. The little house fly (F. canicularis) is an important spring and early summer pest. These flies generally do not impact production directly, although there is some potential for them to transport poultry pathogens among or within operations.

Ongoing residential development on formerly agricultural or open lands near poultry farms has resulted in increasingly frequent land use conflicts between farms and their relatively new suburban neighbors. The main problem with flies is that the presence of too many can trigger nuisance complaints from neighbors and can violate local health ordinances. Egg farm managers can be compelled to implement expensive control strategies or even cease operations if unmitigated problems persist. $M$. domestica and $F$. canicularis were ranked number one and number two in a recent survey of pest importance in California poultry operations (Hinkle and Hickle 1999).

Fly control options include chemical, cultural and biological techniques. Chemical fly control is still common and needed in some situations, with emphasis on the use of fly baits or selective insecticides that kill adult flies applied to surfaces that flies rest on. Overreliance on chemicals often leads to insecticide resistance, and direct application of most fly larvicides (orga- 
nophosphates) to manure is discouraged due to their deleterious effects on the natural enemies of flies. Predatory and parasitic insects and mites in the manure can kill most flies before they become adults.

Cultural control through manure management is critical to fly suppression. More than any other factor, manure management dictates the type and effectiveness of other fly control methods, including chemical and biological. Some poultry producers undertake frequent manure removals, coupled with thin-bed manure drying. Weather conditions, especially rain, can complicate frequent removal. When done properly and frequently enough, however, no flies are produced. This may be the only real option for poultry producers to eliminate flies in urbanized settings, but it also can increase odor and dust problems.

A common management option is allowing the manure to pile up and dry in place beneath the hen cages. Manure can accumulate for several months in open-sided, single-story housing (with the manure only 1 to 3 feet below the hens), or up to 2 years in two-story, deep-pit housing (with manure that falls into a separate pit level below the upper story that houses the hens). In such buildup systems, optimizing manure drying makes the manure less suitable for fly oviposition or development, while encouraging the activity of natural enemies. Fresh manure is about $80 \%$ moisture; this varies with the genetics, diet and age of the hens, as well as air temperature.

Pest flies develop best in fairly moist but not liquefied manure. House flies are abundant at moisture levels of $65 \%$ to $79 \%$, but they are relatively rare at moisture levels below $60 \%$ (Stafford and Bay 1987). A drying, building and aging manure mass actually supports fewer flies, due in part to an increasingly complex assemblage of natural enemies over time (Legner et al. 1973). Key natural enemies include parasitic wasps, which attack fly pupae, as well as predatory mites and hister and rove beetles, which feed on fly eggs and larvae. The most impor- tant wasps in poultry manure are in the genera Muscidifurax and Spalangia (family Pteromalidae), while the key predators are the hister beetle Carcinops pumilio and the mite Macrocheles muscaedomesticae.

Many California poultry producers leave a pad of dry manure as a base when the manure is cleaned out. This pad, often 4 to 8 inches deep, can lessen the intensity of fly outbreaks, which often occur for 4 to 8 weeks after a cleanout (Legner et al. 1973; Meyer et al. 1987). The assumption has been that the pad serves as a natural enemy refuge. Possible physical and chemical effects of the pad, such as absorption of moisture by the dry manure, have been mentioned in the literature but not tested. Many of the predators and immature fly prey, which are most abundant in upper levels of accumulated fresh manure, are removed at cleanout (Wills and Mullens 1991). Flies colonize and reproduce in manure faster than most of their natural enemies, a factor that probably contributes to fly proliferation immediately after a manure cleanout.

We studied several aspects of manure management in the context of fly control in inland Southern California. First, we wanted to know whether the residual manure pad actually helped manure drying and, if so, how it worked. Second, we wanted to document the effects of a typical cleanout on flies and key predators. Third, it has been recommended, without testing at a normal field scale, that manure should be removed in an alternating pattern, that is, removing only part of the accumulated manure at a time. The recommendation was to maintain high populations of natural enemies near cleaned areas so that they can recolonize faster at new, nearby manure deposits. We wanted to determine if this previously untested technique preserves predators and assists in fly control.

\section{Manure pad aids manure drying}

We conducted studies on two poultry ranches in Riverside and San Bernardino counties (one in cooler spring
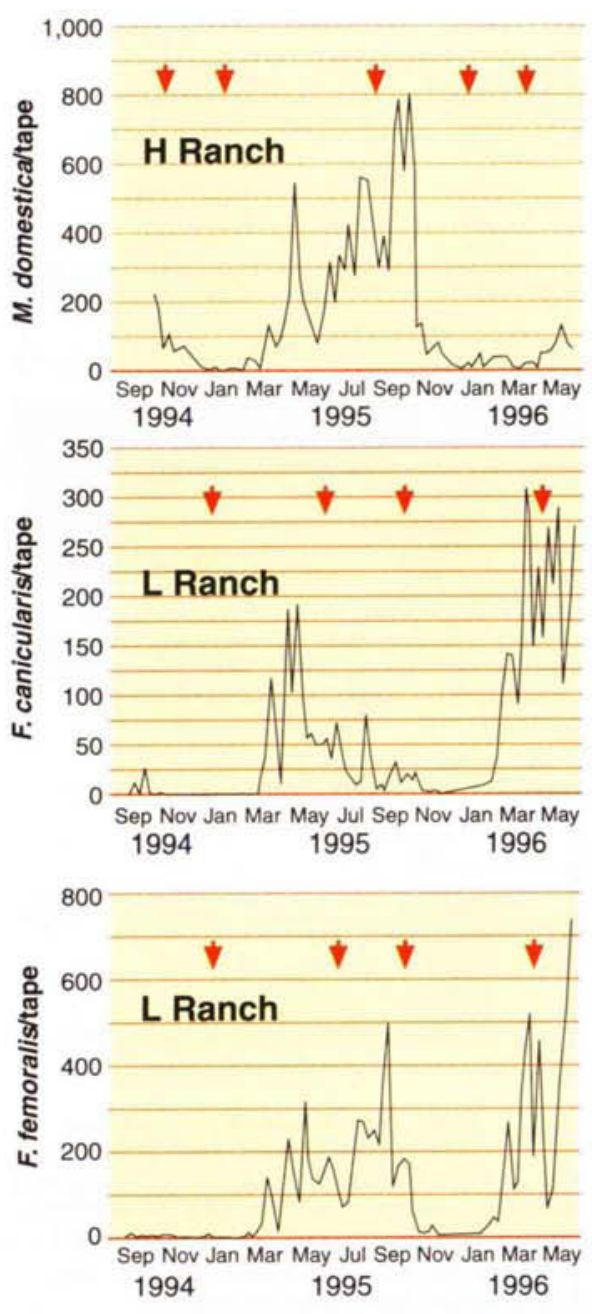

Fig. 1. Representative seasonal abundance patterns of adult house fly (top), little house fly (middle) and coastal fly (bottom) collected on sticky tapes in caged-layer houses in Riverside and San Bernardino counties. Manure cleanouts at designated sites are marked by arrows.

conditions and one in summer) to test whether the old dry pad absorbed moisture directly from the new manure. Wetter surface manure was scraped away from 10 sections in the spring test and 20 sections in the summer test. The sections were on top of an 8-to-10-inch deep, dry (estimated $40 \%$ moisture) pad. Pieces of window screen, 4 inches square, were placed on top of the dry manure pad (section). One screen had a piece of plastic below to prevent contact between new manure and the base. Falling manure penetrated the other piece of screen to contact the dry pad. After 1 week, the accumulated manure was returned to the laboratory, weighed wet, oven 

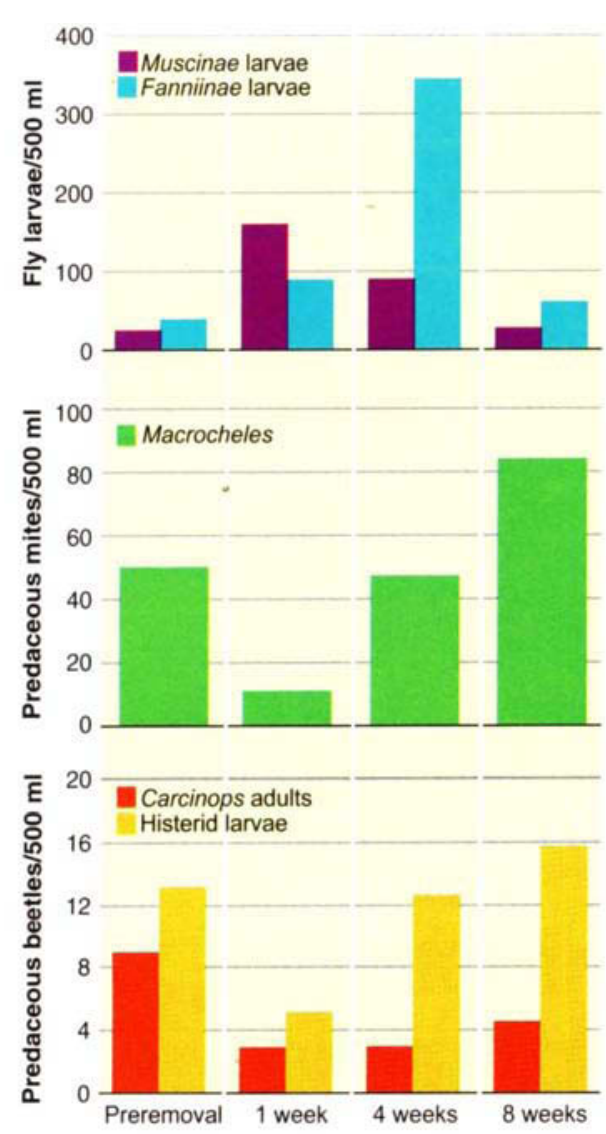

Time relative to manure cleanout

Fig. 2. Pest flies are more abundant after a manure cleanout. House flies (Muscinae) have a shorter life cycle and respond faster than little house flies (Fanniinae). Numbers of both species regain preremoval levels in about 8 weeks. Cleanout also greatly reduces numbers of fly predators; mites reproduce more quickly and recover faster than beetles.

dried and weighed again. The moisture level in the two treatments was approximately the same; $64 \%$ to $65 \%$ in both treatments in the spring and $55 \%$ to $58 \%$ in the summer. The dry pad did not seem to have a role in moisture absorption from the fresh manure.

Next we collected fresh manure after a complete cleanout to ground level in summer and fall. Manure was allowed to accumulate for 1 week on a piece of 4-inch-square screen plus plastic on the soil, or on a screen plus plastic on top of a 5-inch-tall block of wood. The elevated manure was significantly drier, $15 \%$ drier in fall and $37 \%$ drier in the summer.

Using a hot-wire anemometer, we measured airflow at 24 locations in a
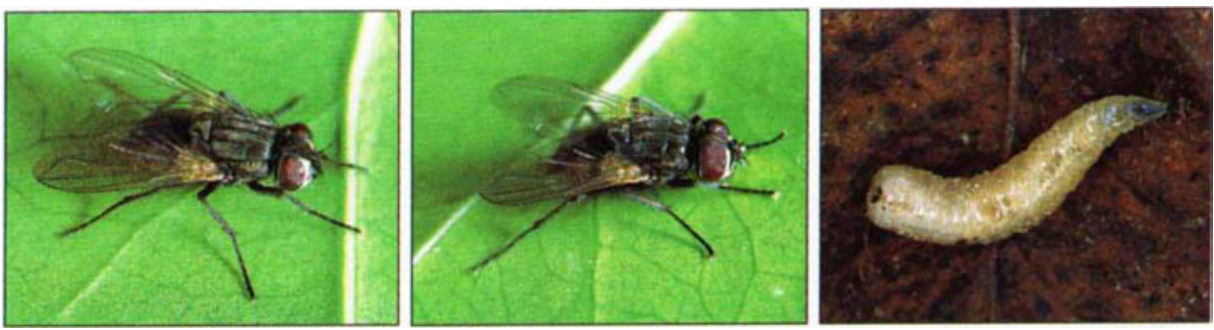

While they do not affect production, an overabundance of flies can be a nuisance to neighbors of poultry egg farms. Adult female, left, male, middle, and larva, right, of the house fly (Musca domestica). Flies lay their eggs in fresh poultry manure. Photos by Jack Kelly Clark.

perimeter row of one poultry house. Air movement was measured in three places: (1) adjacent to the manure surface ( 0.8 inches away) at a height of 0.8 inches (base of the pile); (2) 6 inches (about halfway up the pile); and (3) 10 inches (top of the pile) from the floor. Wind speed was 1.5 feet per second at the top of the pile, 0.9 feet per second halfway up the pile, and only 0.3 feet per second at the base of the pile. The difference in manure drying with height is probably attributable to increased airflow.

Building manure typically does not accumulate evenly, but rather builds into peaks and valleys. Our blocks probably approximated the best drying condition on top of a manure peak. It is fairly safe to say that elevated manure will dry better in most situations. While the pad does not actually absorb significant moisture, it elevates manure and improves drying, probably decreasing the manure's suitability for fly development (Mullens et al. 1996b).

\section{Cleanouts increase flies}

Producers know by experience that disturbing the manure with a cleanout often results in more flies for 1 to 2 months. It has been assumed that manure cleanouts, even leaving a dry pad, probably reduce fly predators.

We monitored six houses on each of two caged-layer ranches for 2 years. A third ranch (with four houses) was monitored for 1 year. Each house received two sticky fly tapes, which we changed every week. Adult flies were identified and counted, providing a general idea of fly activity on the ranch over time.

Our main sampling effort, however, focused on the manure. Each house had four rows of manure. When poultry producers cleaned out the manure (every 3 to 6 months, depending on the ranch), we designated half of the houses to receive normal cleanout and half to receive alternate-row cleanout. In the normal cleanout, most manure was removed, but at least a thin pad of older, dry manure ( 2 to 8 inches thick) usually was left. In the alternate-row removal houses, every other row was removed (leaving a similar pad), while the other two rows were undisturbed. After 1 month, the producers went into the alternate-row houses to clean out the remaining manure.

Samples were taken before removal and 1 week, 4 weeks (before secondary manure removal in the alternate-row houses), and 8 weeks after initial removal. We sampled manure from four equidistant locations in each row on each sampling date, pooling the samples for that row. A small manure sample (4 ounces each, 16 ounces total per row) was taken from the top inch of fresh manure and later exposed to light and heat (Berlese funnels) to extract fly larvae and predators into alcohol in jars. A larger sample (1 quart each, 1 gallon total per row) was taken nearby from the top 3 to 4 inches of fresh manure and placed into an emergence trap. These were held in the house, under normal environmental conditions for that house and season, for 7 weeks. This was long enough for flies to complete emergence. The flies were then identified and counted.

Fly abundance on sticky tapes (fig. 1) showed that house flies usually were a summer and fall (July to November) problem; a spring problem on one ranch was related to adding new hens that voided very wet manure. Little house fly (F. canicularis) and the related $F$. femoralis were common in spring (March to June), but $F$. femoralis was also common in summer and fall. 

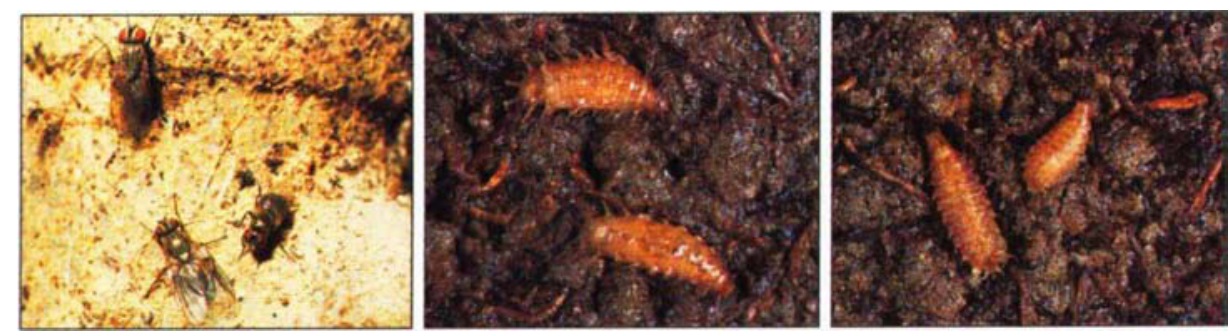

Manure cleaning methods can have an impact on fly populations. Left, Adults of the larger little house fly (Fannia canicularis) and smaller coastal fly (Fannia femoralis). Larvae of the little house fly, middle, and coastal fly, right, are similar in appearance. Photos: Adult flies by Lorry Dunning; larvae by Jack Kelly Clark.

Overall, in the two primary study sites, $28 \%$ of 110,286 adult Fannia on the sticky tapes was canicularis, while the remainder was femoralis. In marked contrast, only $1 \%$ of the total 325,334 emerging Fannia in the emergence traps was F. canicularis; $99 \%$ was femoralis. The difference relates to flight behavior of the two species. $F$. femoralis adults tend to stay near the manure, while $F$. canicularis is a more active flier and disperser to neighboring residences. This makes $F$. femoralis an insignificant fly pest relative to $F$. canicularis. However, their larvae look almost identical, and fly inspectors routinely confuse them. F. canicularis can be common in poultry manure, but the presence of unidentified Fannia larvae should be viewed cautiously. In many cases the larvae could be the relatively nonpestiferous $F$. femoralis.

Manure cleanout caused a shortterm resurgence in flies at all three sites (fig. 2). Larvae of Muscinae (mainly $M$. domestica) were abundant in manure 1 week after cleanout, but within 8 weeks their numbers declined almost to preremoval levels. Larvae of the slower-developing Fannia spp. were most abundant 4 weeks after cleanout, but again had declined significantly by 8 weeks.

\section{Fly predator populations}

Important fly predators also were reduced significantly by manure cleanout (fig. 2). One week after cleanout, adults of the beetle C. punilio declined by an average of $68 \%$, hister beetle larvae (mostly C. pumilio) were reduced by $62 \%$, and the mite Macrocheles was reduced by $76 \%$. The residual numbers of predators reflect some persistence of predator adults and immatures in the manure pad left behind, but we also observed the flight of beetle predators when they were disturbed by cleanout. This probably helped the beetles to distribute themselves. In warm weather, the life cycle of the beetles is 4 to 6 weeks, compared with 1.5 to 3 weeks for flies. Adult beetle numbers still had not achieved preremoval levels after 8 weeks, but beetle larvae were very abundant by 4 to 8 weeks after cleanout. The life cycle of the mite M. muscaedomesticae can be as short as 4 to 7 days, and it generally was able to regain preremoval densities by 4 weeks and exceed them by 8 weeks. This predator rebound probably reflected greater numbers of prey such as fly eggs and larvae. Nevertheless, predators lagged behind the flies in recolonizing and reproducing in the new manure. This likely contributed to the fly rebound after manure cleanout.

\section{Encouraging fly predators}

Cleanout cycles. Cleanout cycles differed substantially in seasonal temperatures as well as in numbers of predators and flies. It was useful to examine individual cleanout cycles. We concentrated on 10 cleanout cycles conducted over 2 years.

In general, there was no detectable benefit to having undisturbed manure less than 3 to 4 feet from the disturbed areas (fig. 3). At two sites, the manure rows were separated by concrete walkways about 3 feet wide. As noted, some beetles and mites remained in the pad and in the fresh manure scattered around it after a cleanout. After 1 week and 1 month, however, predator numbers were no higher in cleaned rows when undisturbed manure was nearby compared with houses in which all the manure had been removed. It appears that both beetles and mites do not readily disperse even a short distance from older-to-new manure across a narrow concrete bar-

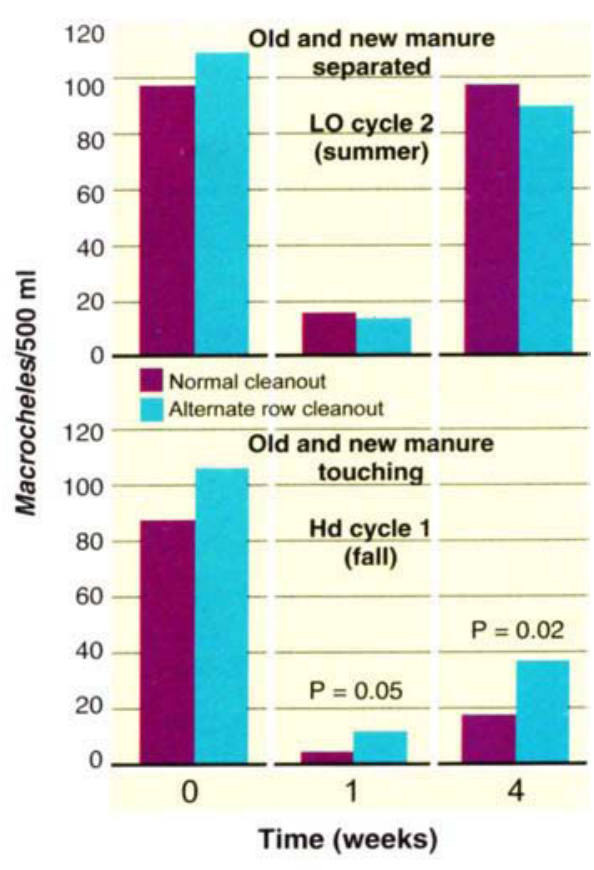

Fig. 3. Leaving alternate rows of undisturbed manure (separated by narrow concrete walkways) usually did not speed recolonization of new manure by fly predators (top). When undisturbed manure was touching the removed manure, predator mites recovered more quickly (bottom).

rier (walkway), despite the much greater abundance of fly prey in new manure deposits.

At one site, the old and new manure areas were in direct contact. For efficiency and cleanliness, most systems are designed to allow cleanout of an entire row of manure rather than only half of it. Still, when old and new manure deposits were touching, it did favor Macrocheles recolonization of the new manure (fig. 3). These predaceous mites have no wings, and can disperse by hanging on to adult flies. Walking, however, is the probable and predominant means of dispersal among nearby manure deposits. Mites could do this only when old and new manure deposits were touching. Given the practical difficulties of doing such a cleanout and the marginal benefits for predator dispersal and fly control, it is difficult to recommend this practice.

Reducing fly outbreaks. Overall, alternate-row removal of manure had no statistically significant benefit in reducing numbers of fly larvae or emerging adults. For Musca these reductions averaged $5 \%$ to $7 \%$ and for Fannia they were $4 \%$ to $15 \%$. Cleaning 

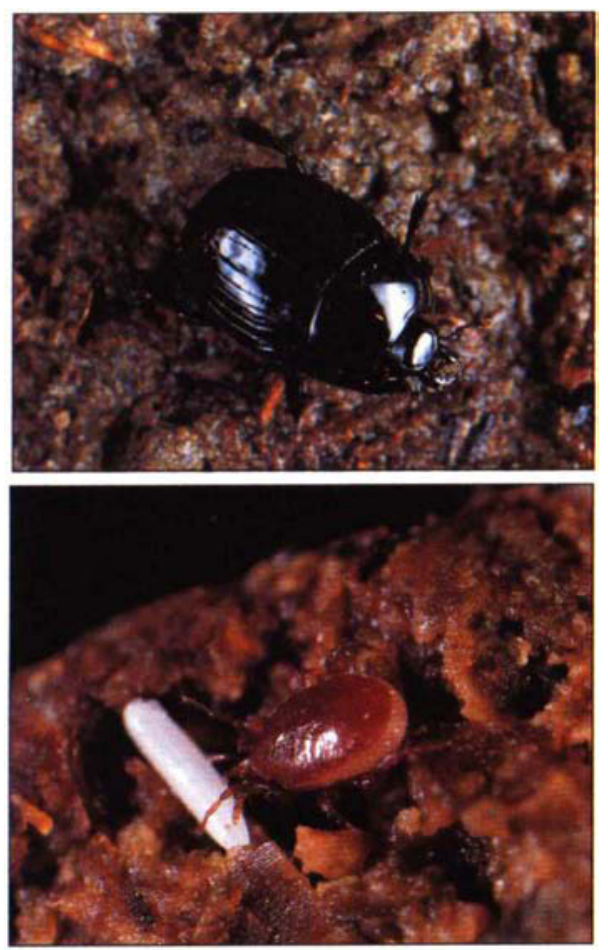

Key predators of pest fly eggs and larvae in poultry manure are hister beetles, above, and the mite Macrocheles muscaedomesticae, below. Most fly predators tend not to disperse from manure that has adequate numbers of prey (flies) to eat. Photos by Jack Kelly Clark.

out manure in two stages theoretically adds little to overall cost or effort, assuming the producers have their own manure removal equipment. In practice, however, they still must arrange to do the work at two different times, dispose of the manure promptly (by selling it for fertilizer, although seasonal demand varies), and perhaps risk weather changes in the interim.

The cleanout cycle at one farm illustrated this risk. Primary cleanout occurred in February, resulting in the expected minor increase in Fannia. However, 1 month later the weather was warmer and fly oviposition pressure was greater. The secondary cleanout in the alternate-row removal houses resulted in very high Fannia numbers in the (fortunately) small amount of manure disturbed at that time.

Any disturbance of established manure can stimulate a fly outbreak, but there are periods of greater risk. Our studies were not designed to look specifically at cleanout timing. However, the best times to avoid fly outbreaks appear to be approximately December-January (after house fly season but before large numbers of adult Fannia are active) and June (after Fannia season but before large numbers of house flies are active). Late summer to early fall and early to mid-spring are peak periods of adult activity for house flies and Fannia, respectively. Cleanouts at these times provide large numbers of adult flies with moist, relatively predator-free manure in which to develop.

In typical, open-sided buildup systems that leave a pad, it appears that alternate-row removal is not effective in reducing fly numbers (Mullens et al. 1996). Some predators redistribute themselves when manure is disturbed or they persist in the pad. The opensided design might allow at least some entrance of natural enemies from adjacent houses.

The situation may differ in newer, deep-pit, environmentally controlled houses. Too few of these exist in Southern California for us to test them experimentally. Manure in deep-pit houses often is cleaned out completely, however, and the houses are relatively sealed. This could impede reestablishment of predator populations, which can take months, especially under cooler temperate conditions (Tobin et al. 1999). In deep-pit systems in the eastern United States, some producers attempt to collect predatory beetles (Carcinops) before a cleanout and then release them again into the house afterward. However, it is possible that poultry disease agents may be introduced along with the beetles, especially if beetles are transferred between houses or sites (Kaufman et al. 2000).

We also do not yet know how alternate-row cleanouts might affect parasitic wasps. Our data suggest that key predators are not particularly effective dispersers even under optimal conditions and that they may take weeks to move between established manure and new habitat only a few feet or yards away. Alternate-row re moval in deep-pit or similar systems therefore might still yield significant benefits for predator conservation and fly control over several months.
B.A. Mullens is Professor, N.C. Hinkle is former Associate Cooperative Extension Specialist and C.E. Szijj is Staff Research Associate, Department of Entomology, UC Riverside; D.R. Kuney is Poultry Farm Advisor, UC Cooperative Extension, Moreno Valley. We are grateful to Rod Bunky, John Gould, Harry Hatanaka and Jim Hoover for their cooperation, to Teresa Chin for technical assistance, and to the late William D. McKeen for advice and assistance in locating study sites.

\section{References}

Axtell RC, Arends JJ. 1990. Ecology and management of arthropod pests of poultry. Ann Rev Entomol 35:101-26.

Hinkle NC, Hickle LA. 1999. California caged-layer pest management evaluation. $J$ Appl Poultry Res 8:327-38.

Kaufman PE, Rutz DA, Pitts CW. 2000. Pest Management Recommendations for Poultry. Cornell and Penn State University Cooperative Extension Pub. University Park, PA. $24 \mathrm{p}$

Legner EF, Bowen WR, McKeen WD, et al. 1973. Inverse relationships between mass of breeding habitat and synanthropic fly emergence and the measurement of population densities with sticky tapes in California inland valleys. Environ Entomol 2:199-205.

Meyer JA, McKeen WD, Mullens BA. 1987. Factors affecting control of Fannia spp. (Diptera: Muscidae) with cyromazine feedthrough on caged-layer facilities in Southern California. J Econ Entomol 80:817-21.

Mullens BA, Hinkle NC, Szijj CE. 1996a. Impact of alternating manure removal schedules on pest flies (Diptera: Muscidae) and associated predators (Coleoptera: Histeridae, Staphylinidae; Acarina: Macrochelidae) in caged-layer poultry manure in Southern California. J Econ Entomol 89:1406-17.

Mullens BA, Hinkle NC, Sziji CE. 1996b. Role of the poultry manure pad in manure drying and its potential relationship to filth fly control. J Agric Entomol 13:331-7.

Stafford III KC, Bay DE. 1987. Dispersion pattern and association of house fly, Musca domestica (Diptera: Muscidae) larvae and both sexes of Macrocheles muscaedomesticae (Acari: Macrochelidae) in response to poultry manure moisture, temperature and accumulation. Environ Entomol $16: 159-64$

Tobin PC, Fleischner SJ, Pitts CW. 1999. Spatio-temporal dynamics of resident and immigrating populations of Carcinops pumilio (Coleoptera: Histeridae) in high-rise poultry facilities. J Med Entomol 36:568-77.

Wills LE, Mullens BA. 1991. Vertical distribution of dipterous larvae and predatory arthropods in accumulated caged-layer poultry manure in Southern California. J Agric Entomol 8:59-66. 